1 Universidade Estadual Vale do Acaraú (UVA). Escola de Formação em Saúde da Família Visconde de Sabóia (EFSFVS) Sobral (CE), Brasil. socorroad@gmail.com

2 Universidade Estadual Vale do Acaraú (UVA) Escola de Formação em Saúde da Família Visconde de Sabóia (EFSFVS) Sobral (CE), Brasil. noraneylima@gmail.com

3 Universidade Estadual Vale do Acaraú (UVA). Escola de Formação em Saúde da Família Visconde de Sabóia (EFSFVS) -

Sobral (CE), Brasil. reginaldo.fp@hotmail.com

4 Universidade Estadual do Ceará (Uece) - Fortaleza (CE), Brasil.

rocineideferreira@gmail.com

\section{A tutoria como dispositivo de apoio a um Sistema Municipal de Saúde}

\author{
Mentoring as a device to support a Municipal Health System \\ Maria Socorro de Araújo Dias', Noraney Alves Limaㄹ, José Reginaldo Feijão Parente? , Maria \\ Rocineide Ferreira da Silva ${ }^{4}$
}

RESUMO Neste artigo, abordou-se a função apoio realizada pela tutoria no contexto de um Sistema Municipal de Saúde. Trata-se de estudo de caso ancorado em uma epistemologia qualitativa. Tem como cenário um município do semiárido nordestino. Os dados apresentados originam-se de documentos e entrevistas em profundidade realizadas com trabalhadores(as) que exercem a função de tutoria. O referencial de examinação dos dados foi a análise de conteúdo. A construção histórica do papel do tutor, suas concepções, atribuições e contribuições revelam que este trabalhador tem exercido a função apoio, movendo-se do apoio institucional ao apoio pedagógico, promovendo uma síntese complexa, que articula estas duas dimensões de apoio.

PALAVRAS-CHAVE Tutoria. Preceptoria. Aprendizagem. Educação em saúde.

ABSTRACT In this article, the support function performed by mentoring in the context of a Municipal Health System was discussed. It is a case study anchored in a qualitative epistemology. It has as scenery a municipality of the northeastern semi-arid region. The data presented come from documents and in-depth interviews conducted with workers who perform the mentoring function. The data analysis benchmark was content analysis. The historical construction of the role of the tutor, his conceptions, attributions and contributions reveal that this worker has exercised the support function, moving from institutional support to pedagogical support, promoting a complex synthesis, that articulates these two dimensions of support.

KEYWORDS Mentoring. Preceptorship. Learning. Health education. 


\section{Introdução}

Reconhecendo a fundamental importância da formação, e o consequente desenvolvimento dos trabalhadores do Sistema Único de Saúde (SUS) como condição para a reorientação do modelo de saúde, em um município de médio porte populacional do semiárido nordestino, concebeu-se e implementou-se, no tal ente federativo, a partir de 1997, um conjunto de ações inovadoras. Para apoiar várias dessas ações, o sistema demandou a presença de um trabalhador capaz de produzir as articulações e mediações entre os vários segmentos envolvidos. Esse profissional passou a assumir uma série de responsabilidades e desafios.

No município estudado, esse trabalhador foi inicialmente denominado preceptor de território, passando posteriormente a assumir a designação de tutor do Sistema Municipal de Saúde (SMS). A orientação teórico-metodológica inicial era que esse trabalhador atuasse com foco no território, tendo como cenário de aprendizagem e intervenção o lócus do trabalho (SOUZA ET AL., 2008).

Este artigo aborda a tutoria enquanto dispositivo de apoio, tendo como cenário um SMS. Como dispositivo, entende-se, com base em Deleuze (1989), um constructo operatório multilinear, que se funda em três grandes eixos: saber, poder e produção de modos de subjetivação. Dentro desta concepção, trata-se de um conceito-ferramenta utilizado para identificar ou analisar arranjos capazes de disparar movimentos transformadores. Nesta perspectiva, a função apoio é compreendida enquanto um campo relacional baseado em uma filosofia e em uma metodologia de ajuda.

A relevância de se operar com o dispositivo do apoio no processo de trabalho da tutoria, no âmbito de um SMS, está no fato de que este favorece a participação dos sujeitos na gestão de seus processos de trabalho e da própria organização, como também tende a contribuir para a constituição de espaços coletivos (CASTRO, 2011).
Nesse modelo, o tutor tem como lócus de atuação o território. Este, na perspectiva proposta por Santos e Rigotto (2011), é concebido como espaço que, além de características físicas, expressa, também, perfil histórico, demográfico, epidemiológico, administrativo, político, social e cultural. A pessoa que atua na tutoria enquanto apoiador institucional e pedagógico trabalha de forma orgânica nos processos de educação permanente, em um SMS, na perspectiva da (re)organização dos serviços e da gestão participativa.

Diante dessa complexidade de cenários, práticas e sujeitos, coloca-se a seguinte questão: quais as concepções, atribuições e contribuições da tutoria enquanto função apoio de um SMS?

Com este estudo, espera-se contribuir com a sistematização e a disseminação de saberes (cognitivos, afetivos e práticos) produzidos pela tutoria, no âmbito de um SMS. Pretende-se, também, fornecer novos elementos que ajudem a ressignificar a categoria da tutoria, e que ainda subsidiem o fortalecimento do SUS. Nesta perspectiva, objetiva-se analisar a atuação da tutoria como dispositivo de apoio de um SMS.

\section{Material e métodos}

Estudo de natureza qualitativa, do tipo estudo de caso (YIN, 2005). A opção por esta modalidade de investigação se deu em função da natureza do objeto e do perfil dos sujeitos, que demandam considerar aspectos históricos, subjetivos e relacionais. Utilizaram-se, como técnicas de coleta de dados, a análise documental e a entrevista em profundidade. Elegeram-se, como documentos, portarias relativas à área da educação na saúde e projetos político-pedagógicos relativos à atuação dos tutores do SMS estudado. Tudo isto, considerando os seguintes critérios: representatividade, multiprofissionalidade e acessibilidade. Foram entrevistados nove tutores. As entrevistas foram 
gravadas, degravadas, categorizadas e interpretadas segundo a análise de conteúdo de Bardin (2011).

A pesquisa foi submetida e aprovada por um Comitê de Ética em Pesquisa com Seres Humanos, sob o parecer $\mathrm{n}^{\circ} 503.931$.

\section{Resultados e discussão}

Os resultados focalizam três tópicos, que emergiram dos processos de escuta, com vistas a responder o objetivo antes delineado, a saber: Construção histórica das concepções da tutoria em um SMS; Atribuições da tutoria em um SMS; e Contribuições da tutoria para o SMS.

Para melhor situar os sujeitos trabalhadores que exercem a função da preceptoria no contexto examinado, vale ressaltar que, atualmente, há 14 profissionais desenvolvendo a função apoio, com vistas a promoverem ações de educação em saúde e apoio à gestão. Estes profissionais se filiam a diferentes formações no campo da saúde. A quase totalidade tem título de mestrado e vêm de diferentes categorias profissionais. Possuem uma jornada de trabalho de 30 horas semanais, distribuídas entre atividades de apoio às Residências Multiprofissionais em Saúde da Família e Saúde Mental, e uma agenda de apoio à gestão local, onde são realizadas ações de educação permanente, acompanhamento de trabalhadores, participação em reuniões de problematização da realidade sanitária local, planejamento e avaliação, entre outras.

\section{Construção histórica das concepções da tutoria em um Sistema Municipal de Saúde}

A historicidade dos acontecimentos que envolvem a categoria da tutoria traz ressignificações em relação à identidade deste trabalhador. Os acontecimentos históricos produzem rupturas no estabelecido, gerando outros devires, que delineiam e entrecruzam os itinerários em um SMS.

A análise da trajetória da 'tutoria' como dispositivo de educação permanente no SMS permitiu identificar concepções relacionadas aos marcos legais, aos fundamentos teórico-metodológicos e ético-políticos.

A primeira proposta político-pedagógica orientadora do SMS foi construída no período de 1999 a 2004. Essa concepção refletia as mudanças do modelo de atenção à saúde estabelecido no 'plano municipal de saúde', dando ênfase à qualificação dos profissionais da atenção básica. Para tanto, se investiu na ideia da tenda invertida, e, acoplada a ela, vem a preceptoria de território (leia-se tutoria).

O contexto organizador é o da 'tenda invertida'. [...] em nosso modelo de formação permanente em 'saúde da família', o espaço que possibilita essa relação educativa é a tenda do aluno. Assim, nossa proposta de formação optou por um modelo denominado de Tenda Invertida, em que um grupo de preceptores (tutores) acompanha as unidades de saúde, tentando transformar esse espaço, originalmente de assistência, em local também de construção de saberes e práticas. (EFSFVS, 2004, P. 20).

Desde seu surgimento no sistema local de saúde, esse trabalhador denominado inicialmente como preceptor de território e, mais tarde, como tutor do SMS, está implicado com o desafio de oferecer apoio mediante a descentralização dos processos em saúde, tomando o trabalho como eixo orientador do seu fazer. A proposta da Tenda Invertida trazia uma dimensão problematizadora do processo de trabalho.

Os discursos dos sujeitos enfatizam o surgimento da figura do preceptor de território (tutor), e a construção do seu saber e do seu fazer nos territórios.

[...] nesse primeiro momento, o preceptor de território era aquele que ia fazer o papel do que 
hoje a gente chama do tutor de território. [...] $E$ esse preceptor de território era justamente essa pessoa que ia semanalmente a uma determinada área [...] onde a gente estava vinculada, e lá tinha o papel de apoiar a equipe nessas discussões das atribuições da equipe dentro deste território adscrito. (Tutor 1).

O preceptor de território [...] foi pensado como aquela pessoa com capacidade de motivação e otimização da atenção primária. (Tutor 2).

[...] Então, pra mim, esse é o tutor. É esse profissional, que está no território para contribuir na condição de apoiador dos processos que acontecem. (Tutor 6).

Embora o termo 'tenda invertida' não esteja presente nos discursos dos sujeitos, foi possível apreender seus sentidos e sua operacionalização. Ademais, estes discursos revelam similaridades entre as concepções e práticas desse profissional.

O diálogo com esses sujeitos à luz dos referenciais teóricos permite inferir que é no cotidiano dos territórios de saúde, junto com a equipe de trabalhadores da Estratégia Saúde da Família (ESF), que os preceptores de território (tutores) se constituem como sujeitos.

Considerando as singularidades de cada contexto político local, do marco legal e da proposta político-pedagógica, percebe-se como vão se entrecruzando e se tecendo os cenários de atuação da tutoria como dispositivo de educação permanente.

Neste ínterim, vão sendo construídos sujeitos produtores de saberes e subjetivações que (re)significam e atualizam as concepções da tutoria. Para ilustrar esta perspectiva, ressaltem-se alguns recortes de elementos textuais que fundamentam a construção histórico-conceitual da tutoria:

[...] tutor, preceptor e orientador de serviço são agentes de escuta, catalisação e facilitação dos processos de aprendizagem do 'sistema municipal de saúde' [...], em particular, dos residentes. Têm especial gosto pelo estudo, pelo trabalho de campo e um forte compromisso com os processos de mudanças orgânicas e de aprendizagens no interior do território do qual são responsáveis. Compete ainda estar problematizando os diferentes fazeres dos residentes e do conjunto de profissionais que atua nos serviços de saúde, refletindo a pertinência desses fazeres para a 'estratégia de saúde da família'. (EFSFVS, 2005, P. 19).

Foram identificadas convergências entre as fontes documentais e as falas dos sujeitos. As concepções identificadas nas propostas político-pedagógicas incidem sobre as concepções dos sujeitos, que oscilam entre o foco no apoio institucional às equipes da ESF e o foco no apoio pedagógico à Residência Multiprofissional em Saúde da Família (RMSF).

[...] esse preceptor de território, ele não precisava ter essa expertise... porque hoje a gente discute muito sobre essa distinção entre campo e núcleo. Então [...], naquela época, o preceptor de território [se referindo ao período de 1999 a 2004], ele tinha que entender era da Estratégia Saúde da Família. De como era que a equipe deveria atuar dentro de um território, de uma responsabilidade sanitária. (Tutor 1 ).

E aí, o tutor, ele trabalhava, apoiava muito [...] os processos que estavam acontecendo no território. E a residência também precisava desse apoiador [...] que facilitasse a ligação dos residentes com a equipe, com os outros espaços do território e com os demais membros da equipe [se referindo ao Projeto Político Pedagógico (PPP), que vigorou de 2005 a 2011]. (Tutor 7).

Outros aspectos importantes, no contexto político e organizacional, que influenciaram positivamente o desenvolvimento da proposta da preceptoria de território, foram apontados pelos sujeitos deste estudo. Destacando-se elementos referentes ao ideário da reforma sanitária, a vontade 
política e a liderança do gestor, como segue:

[...] os preceptores, com a gestão, se reuniam pra discutir estratégias de como resolver alguns problemas que apareciam nas unidades. Na verdade, [...] essas dificuldades, elas eram pequenas, diante do estímulo que todas as pessoas estavam tendo naquele momento. Estamos fazendo diferença no sistema de saúde [...] Naquela época, nós, os primeiros preceptores, abraçamos isso, motivados pelo nosso gestor. (Tutor 2).

Contudo, podem-se identificar algumas divergências entre os elementos textuais e os elementos discursivos, no que diz respeito aos critérios de formação na área da saúde e de vinculação com a equipe de assistência.

O tutor - função de supervisão docente-assistencial no campo de aprendizagens profissionais da área da saúde, exercida em campo, dirigida aos profissionais de saúde com curso de graduação e mínimo de três anos de atuação profissional, que exerçam papel de orientadores de referência para os profissionais ou estudantes, respectivamente, em aperfeiçoamento, especialização, em estágio ou vivência de graduação ou de extensão, devendo pertencer à equipe local de assistência e estar regularmente presente nos ambientes onde se desenvolvem as aprendizagens em serviço. (BRASIL, 2005, N. P.).

Historicamente, o grupo de tutores não pertence às equipes da ESF e tem se constituído como coletivo multiprofissional. Esta multiprofissionalidade é reiterada nas falas dos entrevistados, como se pode ver: "[...] Naquela época, tinha muita gente. [...] era gente de áreas bem diversas, né? Enfermagem, medicina e odontologia [...]" (Tutor 2).

Para Pagani e Andrade (2012), a 'preceptoria de território' foi fruto da proposta educativa que era responsável pelo processo de educação permanente dos profissionais, nos territórios de saúde da família, sendo que sua concepção tomou forma através da ação de um grupo multiprofissional, que se apoiou conceitualmente nas noções de 'território', 'Estratégia Saúde da Família' e 'educação permanente'.

Considerando o caráter ético e político da tutoria enquanto dispositivo apoiador dos processos de educação na saúde, sabe-se que este trouxe implicações relativas aos modos de ver a si mesmo e de falar de si, que podem se converter em modos de autojulgamento e de definição do curso de suas próprias ações. Assim como a identidade refletida no outro.

Para Larrosa (1994, P. 37):

[...] as modalidades concretas dos mecanismos éticos, discursivos, jurídicos e práticos que constituem os dispositivos pedagógicos particulares só podem ser entendidas no interior de uma configuração historicamente dada de saber, poder e subjetivação.

Dessa forma, tal resgate histórico permite a contextualização dos processos de autoconsciência, autogoverno, identificação, construção e ativação de critérios jurídicos, normativos e estéticos dos modos de ser tutor e das práticas políticas, pedagógicas e institucionais do SMS, nos seus múltiplos deveres.

\section{Atribuições da tutoria em um Siste- ma Municipal de Saúde}

Em seus estudos de genealogia, Foucault (2000) considera que o sujeito e sua práxis são uma construção histórica. Portanto, cabe descobrir quais elementos estão presentes no saber fazer da 'tutoria do SMS', que permitam a produção destes sujeitos e de suas atribuições.

Os atributos da tutoria podem ser expressos no reconhecimento do diferencial na identificação deste profissional com a Atenção Primária à Saúde, na postura dialógica e no compromisso ético-social, conforme registram as falas a seguir: 
[...] esses [primeiros] preceptores [tutores] acreditavam, e eles não ganhavam muito bem, mas eles estavam movidos por uma intenção, por uma causa que também era deles. [...] Então, foi mais essa crença de estarmos no caminho certo. (Tutor 2)

Então, eu acho que o nosso papel ainda é de todo mundo [...] nós tínhamos algumas pessoas, que vinham dos movimentos sociais, que vinham do trabalho comunitário, do trabalho com movimentos sociais. [...] Eu vejo que a função de preceptor, o papel de tutor hoje foi algo que foi construído historicamente. [...] esse papel já foi bem consolidado. (Tutor 5).

[...] ele vai estar contribuindo para a maior efetividade das ações de saúde, que vai ter aquele olhar pra contribuir na organização de serviço, que vai estar fomentando a ponte de educação permanente. Aí, ele também vai estar apoiando as ações de Nasf [Núcleos de Apoio à Saúde da Família] e de residência. Então, tudo que está acontecendo no território, referente à promoção da saúde, as ações de saúde, o tutor, ele vai estar colaborando diretamente, inclusive, em ações que sejam mais voltadas pra própria equipe de saúde. No sentido de trabalhar alguma situação de mediação de conflito, de organização de servico, de pensar estratégias [...] inovadoras mesmo, pra o enfrentamento de alguns problemas, que a gente não consegue perceber muitas alternativas. (Tutor 6).

Essa diversidade de atribuições é influenciada por alguns elementos presentes em momentos de mudanças, no marco legal, nos fundamentos teóricos e nas políticas de saúde. Entre as atribuições percebidas pelos sujeitos desta investigação, chamam atenção: tutor como apoiador da ESF; tutor do SMS, como apoiador institucional e matricial; tutor como educador, mentor e orientador; tutor como mediador e articulador; tutor como apoiador pedagógico à RMSF; e tutor do SMS como apoiador da gestão, da equipe, dos residentes e da comunidade.
No regulamento da RMSF, estão previstas as seguintes atribuições da tutoria:

I. Reconhecer as bases conceituais da ESF e do SUS e a realidade sócio-cultural-epidemiológica do território;

II. Colaborar com os residentes na organização dos serviços dos Centros de Saúde da Família;

III. Contribuir para o aprofundamento técnico-científico dos residentes e dos profissionais da equipe do Centro de Saúde da Família;

IV. Garantir que os residentes participem de processo formativo, para que intervenham, junto com a equipe, nas situações-problema encontradas no território;

V. Garantir que os residentes participem de processo formativo, para que contribuam na organização e no funcionamento de grupos;

VI. Avaliar o processo formativo de cada residente (SOBRAL, 2008).

O documento destaca algumas atribuições especiais da atuação da tutoria:

I. Promover a integração dos residentes com os outros profissionais e a comunidade;

II. Promover a integração do residente com as redes sociais do território;

III. Colaborar na organização do processo de trabalho dos residentes, na perspectiva da interdisciplinaridade (SOBRAL, 2008).

$\mathrm{Na}$ sua maioria, os discursos dos sujeitos convergem em relação à normativa acima, testemunhando as atribuições do tutor como apoiador pedagógico e institucional do SMS, indicando que suas atribuições suplantam 
a dimensão de apoio pedagógico à RMSF, colaborando para a compreensão de apoio institucional e pedagógico ao SMS.

O tutor, ele também é esse profissional que vai colaborar na integração das ações de ensino-serviço. De maneira que os processos de formação são levados também para o território. [...] Então, o tutor tem esse foco muito forte na Estratégia Saúde da Família, mas ele tem uma responsabilidade que nós esperamos com relação ao projeto de residência. (Tutor 6 ).

As atribuições principais eram mesmo inseri-los no território, dar esse suporte, suporte técnico e pedagógico. Aí, o técnico, o preceptor fazia esse papel e o tutor fazia mais essa questão do pedagógico. (Tutor 8).

Eu vejo o tutor como um apoiador, seja técnico, político, social, humano. Ele é um mediador, que está neste apoio, mediando alguns conflitos, mediando intervenções junto com a gestão, com a equipe, com a própria comunidade. [...] essas atribuições [...] estão relacionadas ao apoio à equipe, à gestão e à comunidade. [...] você precisa ter este apoio técnico pras equipes, mas, assim, este apoio do tutor, ele está muito mais voltado para o apoio pedagógico, para a mudança de atitude [...] a gente consegue trazer essa reflexão para a comunidade [...]. (Tutor 9).

O fazer da pessoa do tutor se viabiliza enquanto dispositivo de apoio. Portanto, se reconhece que o tutor apoiador deve, no seu processo de trabalho, fomentar a construção de espaços coletivos nos quais diferentes atores possam se engajar no enfrentamento de problemas e no desenvolvimento de soluções partilhadas, reconhecendo que todo este processo é atravessado por relações de poder, afetos e saberes (OLIVEIRA ET AL., 2017).

Os sujeitos entrevistados trazem de forma mais ampla as atribuições do 'tutor', principalmente no que diz respeito à potencialização dos espaços coletivos de cogestão, educação permanente em saúde, educação popular em saúde e controle social, como se vê a seguir:

Enxergo o tutor como esse educador comunitário. Isso também dá um crescimento muito grande pr'a gente, porque a gente tem a oportunidade de estar em vários grupos comunitários e facilitar processos, facilitar encontros, facilitar mudanças. Desencadear alguns momentos que a equipe, por si só, até pela limitação do olhar técnico, ela não pensaria. (Tutor 7).

De acordo com Freire (2001), educar não deve se limitar ao processo de transmissão de informações, mas, principalmente, produzir transformações no sujeito que aprende e naquele que facilita a aprendizagem, como também na comunidade (território) na qual o educador busca produzir mudanças.

A análise desses dados remete ao reconhecimento de que o exercício da tutoria passa por assumir uma série de compromissos e responsabilidades, tanto de natureza técnica quanto política, institucional e ética, mas, principalmente, pedagógica.

\section{Contribuições da tutoria para o Siste- ma Municipal de Saúde}

O movimento da tutoria no cenário do SMS possibilita constatar uma série de contribuições, que passam pelas rodas dos Centros de Saúde da Família, pelo apoio pedagógico à RMSF, pelos processos de educação permanente, pela territorialização e pelo apoio institucional.

As rodas são espaços de cogestão que possibilitam reflexões acerca das necessidades de saúde, trabalho em equipe, planejamento, avaliação e pactuação dos processos de (re) organização dos serviços.

Então, além desse fazer junto, o preceptor [tutor] tinha um papel importantíssimo nas rodas das equipes. Naquela época, ainda não tinha esse nome: roda. Mas era reunião de equipe. $\mathrm{E}$, estrategicamente, pensar ações para a melhoria do serviço. (Tutor 2 ). 
Segundo Pagani e Andrade (2012), a tutoria é uma prática inovadora de educação permanente para a ESF e para o SUS, devendo possibilitar o crescimento institucional, profissional e pessoal dos que nele atuam.

A gente tinha, também, muito claro a necessidade de potencializar as rodas, de fazer discussões, compreender que isso configura uma lógica da educação permanente. [...] evidenciar o tutor como esse profissional que vai fomentar a educação permanente no território [...]. Então, a gente já percebia que podia estar potencializando essas ações, discutir mesmo o processo de trabalho no território. (Tutor 6).

Sales e Pagani (2004) tecem algumas considerações sobre o que se entende por tutoria, sua natureza, seus objetivos, sua estratégia e pedagogia. Neste sentido, afirmam que:

A contribuição que se pretende com o trabaIho da preceptoria [tutoria], seguramente, está na perspectiva de aprofundamento das culturas (os modos de sentir, pensar, querer, agir sonhar, lutar...), das pessoas que trabalham ou que frequentam as Unidades de Saúde, o sistema de saúde. (SALES; PAGANI, 2004, P. 43).

Verifica-se toda uma diversidade de ações, que se afirmam enquanto contribuições, no que diz respeito à necessidade de inovação e reorganização das práticas de cuidado, assim como, também, na sistematização e no fortalecimento da participação popular e do controle social nos territórios da ESF. As falas dos sujeitos, a seguir, evidenciam estas contribuições, a partir da atuação dos tutores (preceptores):

A gente também participava desse momento e convidava a comunidade, nesse momento da territorialização, e [...] era feita dentro de um espaço público, de um equipamento social na comunidade. E aquela comunidade era convidada a pensar. Primeiro, a ver suas necessidades, de reafirmar que aquela necessidade existia e de ajudar a equipe a identificar pessoas, lideranças que pudessem se comprometer com aquela situação, se responsabilizar junto na solução do problema. (Tutor 1)

[...] a gente tinha um cronograma nos territórios, participávamos de rodas alternadas porque eram várias equipes [...] quando era período de planejamento, a gente fazia um cronograma. [...] atividades que a gente fazia muito era a territorialização, planejamento, visita domiciliar com eles. Observava, também, o próprio atendimento individualizado [...] os grupos que eles participavam. (Tutor 4).

[...] todas as equipes da atenção básica se reuniam e ali se desencadeava um processo de educação permanente. Nestes encontros [...] eram escolhidas algumas temáticas problemáticas para serem abordadas dentro de uma perspectiva coletiva mesmo. (Tutor 2 ).

Importante constatação deste estudo acerca das contribuições da tutoria é quanto à centralidade do Apoio Paideia, como referência das atividades desenvolvidas pelos tutores nas rodas e nos coletivos do território, da residência e nos espaços de controle social. Como bem dizem os sujeitos a seguir:

Houve um esforço grande nos territórios, pra que a gente conseguisse desenvolver o pacto intersetorial. Mas a gente desenvolveu ações também no [...] Grupo de Trabalho sobre Drogas. Acho que é uma experiência que a gente teve que foi exitosa [...] foi uma ação que a gente conseguiu levar discussões importantes para a comunidade [...] em relação à prevenção do uso de drogas no bairro, articulando mesmo vários segmentos. (Tutor 6).

Um dos trabalhos que eu desenvolvi [...] foi o Fórum Comunitário, que marcou bastante, porque lá não existia conselho local. E a gente conseguiu desenvolver um bom trabalho junto à equipe, articulando o Fórum Comunitário. (Tutor 7). 
Outro trabalho também foi com as Compaz, que eram as comissões que procuravam trabalhar com a promoção da saúde, promoção da cultura de paz nos territórios. [...] Os residentes também se envolveram muito. (Tutor 8 ).

Os resultados evidenciam as contribuições da tutoria para a educação permanente enquanto apoiadores e mediadores nas intervenções juntos à gestão, à comunidade, aos residentes e às Equipes de Saúde da Família (EqSF).

Em relação ao apoio pedagógico à Residência Multiprofissional em Saúde da Família, foram apontados os seguintes pontos positivos, que resultam das contribuições de preceptores de território e tutores do SMS:

[...] um dos projetos que podem evidenciar a figura do tutor como um profissional do sistema saúde-escola é o nível que nós temos de ex-residentes que passaram pela Escola de Saúde da Família. Eles conseguem galgar outro patamar de profissionalização, após sair da residência. Então, vejo que isso é fruto da escola, fruto do processo pedagógico orientado e fermentado pelo tutor. [...] outro ganho que nós temos é a alta aceitação que essa equipe tem para os residentes de saúde da família. É uma aceitação de credibilidade, de trazer realmente a questão da qualidade de vida para aqueles usuários. (Tutor 9).

Os discursos dos tutores reafirmam seu caráter orgânico, pois suas vivências de aprendizagens são construídas a partir das necessidades de saúde identificadas nos territórios junto às equipes da ESF.

Para Campos (2006), uma das vantagens resultantes do Apoio Paideia é a ampliação dos espaços de troca de saberes, que potencializam e amadurecem as equipes para lidar, tanto com aspectos técnicos quanto políticos, humanos ou éticos. Desta forma, o apoiador contribui para o crescimento da capacidade de ouvir e expor críticas, para aceitar derrotas e estabelecer negociações e consensos, nas equipes e nos grupos.

\section{Considerações finais}

Foi trazida, aqui, uma análise da construção histórica da tutoria (preceptoria), considerando concepções, atribuições e contribuições deste dispositivo de apoio com dimensão institucional e pedagógica, no contexto de um SMS. No diálogo com os sujeitos participantes da pesquisa e com os referenciais teóricos, foi possível identificar e compreender os elementos que permitem a produção desses sujeitos, assim como dos saberes e práticas que os instituem como Apoio Paideia.

A partir dos relatos de atividades dos sujeitos pesquisados, observou-se que a tutoria (preceptoria), inicialmente, estava mais voltada para o acompanhamento das ESF e para a reorganização dos seus processos de trabalho. Posteriormente, a tutoria centrou seus esforços no apoio à RMSF, sendo que, mais recentemente, conseguiu desenvolver, de forma articulada e integrada, o apoio institucional e pedagógico.

A práxis da tutoria se efetiva como dispositivo político-pedagógico de apoio, dando ênfase à formação e ao desenvolvimento dos trabalhadores para o SUS, a partir de um modo de atuação como base no apoio institucional, na mediação, na facilitação de processos dialógicos e na pactuação e corresponsabilização entre os sujeitos: docentes, estudantes, gestores, trabalhadores e usuários do SUS.

Considera-se, ainda, que esses profissionais atuaram como problematizadores da realidade de trabalho e de saúde, em um dado território, pretendendo a transformação dessas realidades, instituindo novos processos e relações de trabalho, a partir da implementação de práticas pedagógicas que se apoiam na educação permanente em saúde.

A função apoio aparece muito fortemente nos discursos dos sujeitos, como fundamento da práxis do tutor. Isto pode demonstrar que o Método Paideia se constitui, de fato, como importante referência para o exercício da função apoio pelos tutores. 
Constata-se, ainda, que as rodas dos Centros de Saúde da Família foram bastante citadas pelos sujeitos, relativas às atribuições e às contribuições da tutoria no contexto de um SMS. Pode-se considerar a importância da instituição destes espaços de rodas para a práxis do tutor, tanto na perspectiva do apoio institucional quanto no pedagógico. A função apoio favorece o fortalecimento dos processos de educação permanente, a coprodução de sujeitos, de sentidos, de saberes e de práticas na cogestão dos processos de trabalho vivo em ato na ESF.

\section{Referências}

BARDIN, L. Análise de Conteúdo. São Paulo: Edições $70,2011$.

BRASIL. Ministério da Saúde. Portaria no ${ }^{\circ}$ 1.111/ GM de 05 de julho de 2005. Fixa normas para a implementação e a execução do Programa de Bolsas para a Educação pelo Trabalho. Diário Oficial [da] República Federativa do Brasil. Brasília, DF, 5 jul. 2005. Disponível em: <http://bvsms.saude.gov.br/bvs/saudelegis/gm/2005/prt1111_05_07_2005.html>. Acesso em: 1 jan. 2017. Não paginado.

CAMPOS, G. W. S. Clínica e Saúde Coletiva Compartilhadas: teoria paidéia e reformulação ampliada do trabalho em saúde. São Paulo: Hucitec, 2006.

CASTRO, C. P. Avaliação da utilização do método de apoio Paideia para a formação em saúde: clínica ampliada e cogestão. Campinas: Unicamp, 2011.

DELEUZE, G. Qu'est-ce qu'un disposif? In: MICHEL Foucault philosophe: rencontre internationale. Paris: Seuil, 1989.

ESCOLA DE FORMAÇÃO EM SAÚDE DA FAMÍLIA VISCONDE DE SABÓIA (EFSFVS). Projeto Político Pedagógico. Sobral: EFSFVS, 2004.
. Projeto Político Pedagógico. Sobral: EFSFVS, 2005 .

FREIRE, P. Educação e Mudança. 34. ed. Rio de Janeiro: Paz e Terra, 2011

FOUCAULT, M. Microfísica do poder. Rio de Janeiro: Graal, 2000.

LARROSA, J. Tecnologias do eu e educação. In: SILVA, T. T. O sujeito da Educação: estudos foucaultianos. Petrópolis: Vozes, 1994.

OLIVEIRA, E. A. et al. O apoiador local como ator estratégico na implementação do QualiSUS-Rede: engenheiros de conexão? Saúde em Debate, Rio de Janeiro, v. 41, 2017. No prelo.

PAGANI, R.; ANDRADE, L. O. M. Novas Práticas e Saberes na Estratégia de Educação Permanente em Saúde da Família: o estudo de caso de SobralCE. Saúde e Sociedade, São Paulo, v. 21, supl. 1, p. 94-106, 2012. Disponível em: <http:www.scielo. br/scielo.php?script=sci-arttext\&pid=S0104-12902012000500008Ing=pt \&nkm=iso>. Acesso em: 2 jan. 2017

SALES, I. C.; PAGANI, R. F. A Preceptoria de Território 
na Estratégia Saúde da Família em Sobral/CE (desafios políticos, técnicos e metodológicos de uma experiên-

cia). SANARE: Revista de Políticas Públicas, Sobral, v. 5, n. 1, 2004. Disponível em: <https://sanare.emnuvens. com.br/sanare/article/view/121>. Acesso em: 1 jan. 2017.

SANTOS, A. L.; RIGOTTO, R. M. Território, e territorialização: Incorporando as relações produção, trabalho, ambiente e saúde na Atenção Básica à Saúde. Revista Trabalho Educação e Saúde. Rio de Janeiro, v. 8, n. 3, p. 387-406, 2010. Disponível em: <http://www.scielo.br/scielo.php?pid=S1981$-77462010000300003 \&$ script $=$ sci_abstract $\&$ tlng $=p t>$. Acesso em: 1 jan. 2017.
SOUZA, F. L. et al. A Política Municipal de Educação

Permanente em Sobral-CE. SANARE: Revista de

Políticas Públicas, Sobral, v. 7, n. 2, 2008. Disponível em: <https://sanare.emnuvens.com.br/sanare/article/ view/27>. Acesso em: 1 jan. 2017.

YIN, R. K. Estudo de caso: planejamento e métodos. 3. ed. Porto Alegre: Bookman, 2005.

Recebido para publicação em janeiro de 2017

Versão final em junho de 2017

Conflito de interesses: inexistente

Suporte financeiro: não houve 